\title{
Accelerometer-determined peak cadence and weight status in children from São Caetano do Sul, Brazil
}

\author{
Determinação do pico de cadência via acelerometria e estado \\ de peso corporal em crianças de São Caetano do Sul, Brasil
}

\author{
Gerson Luis de Moraes Ferrari ${ }^{1,2}$ \\ Timóteo Araújo ${ }^{1}$ \\ Luis Carlos Oliveira ${ }^{1}$ \\ Victor Keihan Rodrigues Matsudo ${ }^{1}$ \\ Emily Mire ${ }^{3}$ \\ Tiago Barreira ${ }^{3,4}$ \\ Catrine Tudor-Locke ${ }^{3}$ \\ Peter T. Katzmarzyk ${ }^{3}$
}

\footnotetext{
${ }^{1}$ Centro de Estudos, Laboratório de Aptidão Física de São Caetano do Sul. R. Heloísa Pamplona 269, Fundação. 09520-320 São Caetano do Sul SP Brasil.gersonferrari08@ yahoo.com.br

${ }^{2}$ Centro de Atendimento e Apoio ao Adolescente, Departamento de Pediatria da Universidade Federal de São Paulo. São Paulo SP Brasil.

${ }^{3}$ Pennington Biomedical Research Center. Baton Rouge LA EUA. ${ }^{4}$ Syracuse University. New York NY EUA.
}

\begin{abstract}
The purpose of this study was to determine the relationship between peak cadence indicators and body mass index (BMI) and body fat percentage (BF\%)-defined weight status in children. The sample comprised 485 Brazilian children. Minute-by-minute step data from accelerometry were rank ordered for each day to identify the peak 1-minute, 30-minute and 60-minute cadence values. Data were described by BMI-defined and bioelectrical impedance-determined BF\% weight status. BMI-defined normal weight children had higher peak 1-minute (115.5 versus 110.6 and 106.6 steps/min), 30-minute (81.0 versus 77.5 and $74.0 \mathrm{steps} / \mathrm{min}$ ) and 60-minute cadence (67.1 versus 63.4 and 60.7 steps $/ \mathrm{min}$ ) than overweight and obese children ( $p<.0001)$, respectively. Defined using $\% B F$, normal weight children had higher peak 1-minute (114.5 versus 106.1 steps/min), 30-minute (80.4 versus 73.1 steps $/ \mathrm{min})$ and 60 -minute cadence (66.5 versus 59.9 steps/min) than obese children $(p<.0001)$. Similar relationships were observed in boys; however, only peak 1- minute cadence differed significantly across BMI and $\% B F-d e f i n e d$ weight status categories in girls. Peak cadence indicators were negatively associated with $B M I$ and $B F \%$ in these schoolchildren and significantly higher among normal weight compared to overweight or obese children.
\end{abstract}

Key words Physical activity, Adiposity, Obesity, Body composition
Resumo O objetivo do estudo foi determinar a relação entre indicadores de pico de cadência com indice de massa corporal (IMC) e percentual de gordura corporal (\% GC) definidos pelo estado de peso corporal de crianças. Participaram 485 crianças brasileiras. Minutos de acelerometria foram ranqueados para identificar os valores de picos de cadência de 1, 30 e 60 minutos. O estado de peso corporal foi apresentado pelo IMC e \%GC, avaliados pela bioimpedância elétrica. No IMC, crianças eutróficas apresentaram maior pico de cadência de 1 minuto (115,5 versus 110,6 e 106,6 passos/min), 30 minutos (81,0 versus 77,5 e 74,0 passos/min) e 60 minutos (67,1 versus 63,4 e 60,7 passos/min) do que aqueles com excesso de peso e obesidade $(p<0,001)$. Na \%GC, crianças eutróficas apresentaram maior pico de cadência de $1 \mathrm{mi}$ nuto (114,5 versus 106,1 passos/min), 30 minutos (80,4 versus 73,1 passos/min) e 60 minutos (66,5 versus 59,9 passos/min) do que as obesas. Relações semelhantes foram observadas nos meninos; no entanto, apenas o pico de cadência de 1 minuto foi significativamente diferente nas categorias do estado de peso corporal definido pelo IMC e \%GC nas meninas. Indicadores de pico de cadência foram negativamente associados com IMC e \%GCe maior nos eutróficos do que naqueles com excesso de peso e obesidade.

Palavras-chave Atividade física, Adiposidade, Obesidade, Composição Corporal 


\section{Introduction}

Childhood obesity is an important public health problem that has recently increased dramatically in prevalence in both developed and developing countries ${ }^{1}$. A recent systematic review concluded that higher levels of regular physical activity assessed objectively by accelerometers likely protects against obesity in children and adolescents ${ }^{2}$. The use of accelerometers to measure physical activity generally results in stronger associations with overweight and obesity than the use of questionnaires in children ${ }^{3}$. For example, Ferrari et al. ${ }^{4}$ reported a negative association between objectively measured moderate-to-vigorous physical activity (MVPA) with body composition variables (body mass index (BMI) and body fat percentage (BF\%)) in Brazilian children.

Researchers have used step counts to describe children's and adolescents' daily ambulatory physical activity levels ${ }^{5,6}$. However, steps/day has been criticized because it only provides a total volume of physical activity without information about the intensity. This limitation can be overcome with the use of accelerometers that have the capability of storing minute-by-minute step accumulations, which can be used to quantify stepping cadence (steps/min) as it is naturally expressed in free-living, indicative of a full range of step accumulation patterns and stepping rates ${ }^{7,8}$.

Originally investigated by Hoshikawa et al. ${ }^{9}$, cadence is associated with ambulatory speed ${ }^{10}$ and is a proxy indicator of intensity of ambulatory activity ${ }^{11-13}$. A recent review has introduced the concept of using cadence as a way to study free-living ambulatory behavior ${ }^{14}$. Some studies have used accelerometer step counts to not only describe the total amount of daily ambulation but also different aspects of children's cadence $^{15-17}$. In addition to analyzing cadence to describe movement it is also possible to measure and analyze patterns of peak cadence for different time increments. Peak cadence indicators for children include peak 1-minute (defined as the steps/min recorded for highest single minute in a day), peak 30-minute (average value for top 30 ranked minutes) and peak 60-minute (average value for top 60 ranked minutes) cadence values and can be considered indices of "best natural daily effort" 18,19 .

The relationship between peak cadence and health related variables has been examined in children from developed countries ${ }^{16-18}$. Using data from the 2005-2006 U.S. National Health and Nutrition Examination Survey (NHANES),
Barreira et al..$^{18}$ reported negative associations between cardiovascular disease (CVD) risk factors (in particular, HDL-C, blood pressure, and BMI) and each of the peak cadence indicators in children. Peak 60-minute cadence was lower across groups of children with higher numbers of CVD risk factors (76 steps/min in those without any risk factors versus $67 \mathrm{steps} / \mathrm{min}$ in those with $\geq 2$ risk factors $)^{18}$. In addition, Gardner et al. ${ }^{16}$ reported that children, adolescents, and young adults with metabolic syndrome walked at lower daily average cadence than those without metabolic syndrome (27 versus 30 steps/min), and they had lower cadences for continuous durations of $60 \mathrm{~min}$ (31 versus 38 steps $/ \mathrm{min}$ ), $30 \mathrm{~min}$ (42 versus 50 steps $/ \mathrm{min}$ ), and $1 \mathrm{~min}$ (102 versus $110 \mathrm{steps} / \mathrm{min}$ ). Although popular in use, there are relatively few studies that have used accelerometry to study children in developing countries like Brazil ${ }^{4,20,21}$. The relationship between peak cadence indicators and obesity has not been studied in Brazilian children. Therefore, the purpose of this study was to determine the relationship between peak cadence indicators and weight status (defined by BMI and by BF\%) in children from São Caetano do Sul, Brazil.

\section{Methods}

Data collection was conducted as part of the International Study of Childhood Obesity, Lifestyle and the Environment (ISCOLE). The primary aim of ISCOLE was to investigate the influence of behavioral settings and the physical, social, and policy environments on observed relationships between lifestyle characteristics and weight status in approximately 500 children from each of the included 12 countries (Australia, Brazil, Canada, China, Colombia, Finland, India, Kenya, Portugal, South Africa, United Kingdom, and United States) representing all major world regions. Details of the ISCOLE protocol are provided elsewhere ${ }^{22}$.

The analysis herein focuses only on the data collected in the city of São Caetano do Sul, located in the state of São Paulo, Brazil, with a land area of $15.3 \mathrm{~km}^{2}$ and a subtropical climate. The population of the municipality in 2013 consisted of 149,263 inhabitants, including 1,557 children (812 boys and 745 girls) 10 years of age ${ }^{23}$. The city is characterized as a service economy ${ }^{23}$ and has the best Human Development Index (HDI) in Brazil (0.86) according to the United Nations Program for Development ${ }^{24}$. 
A random cluster sample of $5645^{\text {th }}$ grade Brazilian children (277 boys and 287 girls), aged 9-11 years old, was assessed. After accounting for exclusionary criteria (non-valid accelerometer data as defined below, missing $\mathrm{BMI}$ or $\mathrm{BF} \%$, the final sample comprised 485 children (238 boys and 247 girls)).

Data were collected during the school year from March 2012 to April 2013. All assessments were done during a full week per school. All data collection and management activities were performed and monitored under rigorous quality control procedures, implemented by the ISCOLE Coordinating Center, as described in detail previously $^{22}$. Prior to participating, children and at least one of their parents/legal guardians were asked to sign the Instrument of Consent according to Resolution 196/96 of Brazil's National Health Council. Ethical approval was obtained from the Pennington Biomedical Research Center Institutional Review Board and Federal University of São Paulo, Brazil.

Random lists of public and private elementary schools in the region were generated, and schools were selected from each list at a ratio of 4 (public) to 1 (private). This $80 \%$ public to $20 \%$ private schools ratio was purposely implemented to maximize socioeconomic status distribution. If a school refused to participate in the study, it was replaced by the next school on the list, maintaining the same public to private school ratio. A random sample of 25-30 children was selected to participate per school with a stipulation that each sex comprised $50 \%$ of the selected sample.

The ActiGraph GT3X+ accelerometer (ActiGraph LLC, Pensacola, United States) was used to assess step-defined physical activity. The accelerometer was worn at the waist on an elasticized belt, on the right mid-axillary line. The participants were encouraged to wear the accelerometer 24 hours/day for at least 7 days (plus an initial familiarization day and the morning of the final day), including 2 weekend days. To be included in this analysis, children had to have valid accelerometer data (defined as $\geq 4$ days, including at least one weekend day, with $\geq 10$ hours of wake wear time per day $)^{25,26}$. Overall, $84.7 \%$ of the eligible sample met these criteria. The number of valid days ranged from 4-7, averaging 6.7 days per participant.

Following the final day of data collection, staff went into the school and retrieved the accelerometers. The research team verified the data for completeness using the most recent version of the ActiLife software (version 5.6 or higher;
ActiGraph, Pensacola, United States) available at the time. Nine participants who did not provide adequate data during initial monitoring wore the accelerometer for a second week to ensure that the minimal data requirements were met. The step data were processed with the default filter so as not to over-estimate step counts using the low frequency extension ${ }^{27,28}$.

Due to the 24-hour wear protocol, the nocturnal total sleep episode time was identified and excluded from any analysis of steps/day and physical activity using a published algorithm ${ }^{29}$. Daily minutes of wake wear time were then ranked in descending order of steps $/ \mathrm{min}^{17}$. The value for the highest ranked 1 minute of steps/ min represented the peak 1-minute cadence. Peak 30-minute (highest 30 minutes) and peak 60-minute (highest 60 minutes) cadence represented an average steps/min accumulated during the highest, but not necessarily consecutive, min/ day. Each of these peak cadence indicators was averaged across all valid days ${ }^{6,30}$.

Height, weight and BF\% measures were obtained according to standardized ISCOLE procedures $^{22}$. Height was measured using a Seca 213 portable stadiometer (Hamburg, Germany) ${ }^{31}$. Weight and $\mathrm{BF} \%$ were measured using a portable Tanita SC-240 body composition analyzer (TANITA Corporation, Japan) ${ }^{32}$. Each child was measured twice and, when necessary, a third measurement was taken if the difference between the previous two was outside the permissible range for each measure and its replica $(0.5 \mathrm{~cm}$ for height, $0.5 \mathrm{~kg}$ for weight, and $2 \%$ for $\mathrm{BF} \%)$. The two closest measurements were averaged, and the mean value of each measured variable was used for analysis.

BMI was calculated using the standard formula [weight $(\mathrm{kg}) /$ height $\left.(\mathrm{m})^{2}\right]$ and thereafter, BMI $z$-scores (calculated based on sex- and age-specific growth reference data from the World Health Organization (WHO) for children and youth) were further categorized as normal: $\leq$ 1 SD; overweight: $>+1$ SD to 2 ; and obese: $>+2$ $\mathrm{SD}^{33}$.

We also categorized BF\% according to sexand age-specific cut-points. Specifically, children were categorized as normal weight $\left(<85^{\text {th }}\right.$ percentile of sex-specific reference data from children in the United Kingdom $)^{34}$, overweight $(\geq$ 85th to $<95^{\text {th }}$ percentiles) and obese $\left(\geq 95^{\text {th }}\right.$ percentile).

Descriptive statistics, including means, confidence interval $(95 \% \mathrm{CI})$ or frequencies as appropriate were calculated. Multi-level linear 
regression models were used to examine the associations between peak cadence indicators and $\mathrm{BMI}$ and $\mathrm{BF} \%$. Peak cadence indicators across different levels of weight status defined by BMI and $\mathrm{BF} \%$ (normal weight, overweight and obese) were analyzed in a model that included sex and the sex-by-weight status interaction. Least-squared means were compared across levels of $\mathrm{BMI}$ and $\mathrm{BF} \%$ for the entire sample as well as separately by sex. Multi-level linear regression models were also used to examine the associations between peak cadence indicators and continuous measures of BMI and BF\%; models were adjusted for sex and accounted for school (to allow for clustering at the school level). Statistical Analysis System (SAS, version 9.3) was used for data analyses and $\mathrm{p}<0.05$ was adopted as the significance level ${ }^{35}$.

\section{Results}

The frequency of excess BMI and BF\% status is presented in Table 1. Based on BMI, most children were classified as normal weight $(54.6 \%)$ followed by overweight (23.1\%) and obese (22.3\%). When analyzed separately by sex, $45.8 \%$ of boys and $45 \%$ of girls were overweight or obese according to their BMI-defined weight status. Most children (67\%) were classified as normal weight by $\mathrm{BF} \%$, followed by overweight $(12.8 \%)$ and obese $(20.2 \%)$. By sex, $33.6 \%$ of boys and $32.4 \%$ of girls were classified as overweight or obese by BF\%.

Compared to girls, boys consistently achieved significantly higher values for each of the peak cadence indicators (Figure 1).

Table 2 presents peak cadence indicators across categories of BMI. For the total sample, there were significant differences in each of the peak cadence indicators between BMI-defined weight status categories. Normal weight children achieved significantly higher mean values for each of the peak cadence indicators compared with overweight and obese children (Table 2).

The same relationships were observed when the analysis was focused only on boys: there were significant differences in all peak cadence indicators across BMI-defined weight status categories and normal weight boys had higher mean values obese boys. In contrast, only the peak 1- minute cadence differed significantly across BMI-defined weight status categories in girls.

In the normal weight category, boys achieved significantly higher mean values than girls in all peak cadence indicators, and overweight boys had significantly higher mean values than overweight girls in the peak 60-minute cadence indicator category (Table 2). There were no significant sex differences in the obese category.

Table 3 presents the peak cadence indicators across categories of BF\%-defined weight status. All peak cadence indicators had mean values that differed significantly across BF\% weight status categories. Normal weight children achieved significantly higher mean values than obese children in all peak cadence indicators and overweight children had significantly higher values than obese children for the peak-1 minute indicator (Table 3).

In boys, there were significant differences among the BF\% weight status categories for all peak cadence indicators; normal weight boys had significantly higher mean values than obese boys in all peak cadence indicator categories and significantly more than overweight boys in the peak-60 minute cadence indicator category. Normal weight girls achieved significantly higher mean values than obese girls for the peak 1-minute indicator only (Table 3 ).

Table 1. Frequency (\%) of BMI and BF\%-defined weight status by sex in Brazilian children.

\begin{tabular}{lcrr}
\hline & \multicolumn{3}{c}{ BMI-defined weight status } \\
\cline { 2 - 4 } & Normal & Overweight & Obese \\
\hline Both $(\mathrm{n}=485)$ & $265(54.6 \%)$ & $112(23.1 \%)$ & $108(22.3 \%)$ \\
Boys $(\mathrm{n}=238)$ & $129(54.2 \%)$ & $38(16.0 \%)$ & $71(29.8 \%)$ \\
Girls $(\mathrm{n}=247)$ & $136(55.1 \%)$ & $74(30.0 \%)$ & $37(15.0 \%)$ \\
\hline \multicolumn{4}{r}{ BF\%-defined weight status } \\
\hline Both & $325(67 \%)$ & $62(12.8 \%)$ & $98(20.2 \%)$ \\
Boys & $158(66.4 \%)$ & $26(10.9 \%)$ & $54(22.7 \%)$ \\
Girls & $167(67.6 \%)$ & $36(14.6 \%)$ & $44(17.8 \%)$ \\
\hline
\end{tabular}




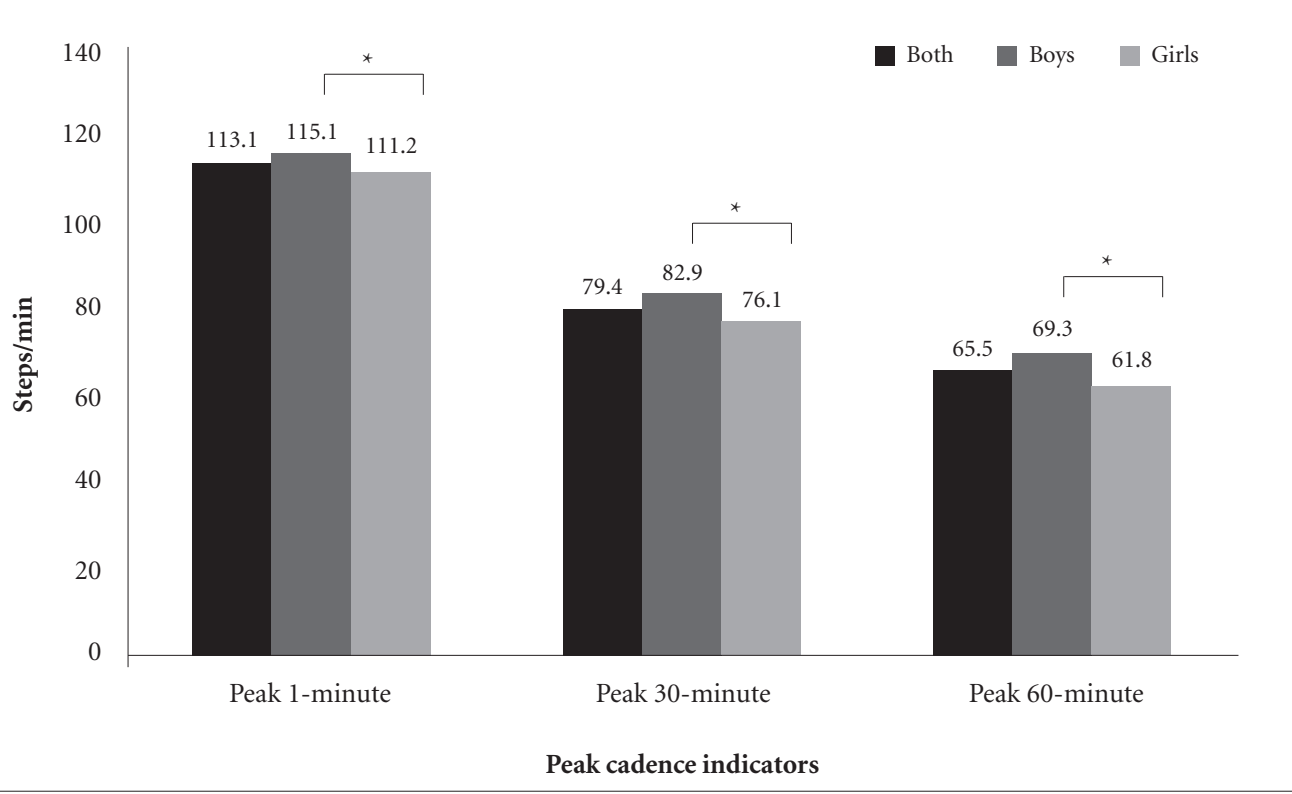

Figure 1. Peak cadence indicators by sex in Brazilian children.

${ }^{\star}$ Significant difference between boys and girls.

Table 2. Descriptive (mean and 95\% CI) analysis of peak cadence indicators according to BMI-defined weight status and sex in Brazilian children.

\begin{tabular}{cccccc}
\hline Peak cadence & \multicolumn{5}{c}{ BMI-defined weight status } \\
\cline { 2 - 6 } Indicator & Sample & Normal Weight & Overweight & Obese & $\mathbf{p}^{\mathbf{a}}$ \\
\hline Peak 1-minute & Both & $115.5(112.5-118.5)^{\mathrm{cd}}$ & $110.6(107.1-114.0)^{\mathrm{e}}$ & $106.6(103.1-110.2)$ & $<.0001$ \\
& Boys & $118.8(115.4-122.2)^{\mathrm{cd}}$ & $111.2(106.5-115.9)$ & $107.1(103.2-110.9)$ & $<.0001$ \\
& Girls & $112.1(108.8-115.4)^{\mathrm{bd}}$ & $109.9(106.1-113.7)$ & $106.2(101.4-111.0)$ & .0448 \\
Peak 30-minute & Both & $81.0(77.3-84.7)^{\mathrm{cd}}$ & $77.5(73.4-81.6$ & $74.0(69.8-78.2)$ & $<.0001$ \\
& Boys & $86.0(82.0-90.0)^{\mathrm{cd}}$ & $79.8(74.5-85.1)$ & $74.9(70.4-79.4)$ & $<.0001$ \\
& Girls & $76.0(72.0-80.0)^{\mathrm{b}}$ & $75.2(70.8-79.6)$ & $73.2(67.7-78.6)$ & .5374 \\
Peak 60-minute & Both & $67.1(63.8-70.4)^{\mathrm{cd}}$ & $63.4(59.7-67.1)$ & $60.7(56.9-64.5)$ & $<.0001$ \\
& Boys & $72.4(68.8-76.1)^{\mathrm{cd}}$ & $66.1(61.2-70.9)$ & $62.0(57.9-66.1)$ & $<.0001$ \\
& Girls & $61.7(58.1-65.3)^{\mathrm{b}}$ & $60.7(56.7-64.7)^{\mathrm{b}}$ & $59.4(54.5-64.4)$ & .6046 \\
\hline
\end{tabular}

BMI: body mass index. ${ }^{a}$ Trend in least-squared means across BMI-defined weight status categories; ${ }^{b}$ significant difference between boys and girls $(\mathrm{p}<.05)$; ${ }^{\mathrm{c}}$ significant difference between normal weight and overweight $(\mathrm{p}<.05)$; ${ }^{\mathrm{d}}$ significant difference between normal weight and obese $(\mathrm{p}<.05) ;{ }^{\mathrm{e}}$ significant difference between overweight and obese $(\mathrm{p}<.05)$.

In the normal weight category, boys accumulated significantly higher mean values than girls in all peak cadence indicators; no sex differences were observed in the obese or overweight categories (Table 3 ).

Table 4 presents the results of the multi-level regression analyses describing the association between each of the peak cadence indicators and BMI and BF\% separately. There were negative significant associations between BMI and all peak cadence indicators as well as between $\mathrm{BF} \%$ and all peak cadence indicators when adjusted for sex and school, indicating that this association is independent of sex and school.

\section{Discussion}

The aim of this study was to determine the relationship between peak cadence indicators and weight status in children from São Caetano do Sul, Brazil, averaging 10 years of age. We demon- 
Table 3. Descriptive (mean and 95\% CI) analysis of peak cadence indicators of according BF\% status and sex in Brazilian children.

\begin{tabular}{cccccc}
\hline \multirow{2}{*}{$\begin{array}{c}\text { Peak cadence } \\
\text { Indicator }\end{array}$} & \multicolumn{5}{c}{ BF\% status } \\
\cline { 2 - 6 } & Sample & Normal Weight & Overweight & Obese & $\mathbf{p}^{\mathrm{a}}$ \\
\hline \multirow{3}{*}{ Peak 1-minute } & Both & $114.5(111.6-117.4)^{\mathrm{d}}$ & $111.1(107.0-115.1)^{\mathrm{e}}$ & $106.1(102.5-109.7)$ & $<.0001$ \\
& Boys & $117.4(114.2-120.6)^{\mathrm{d}}$ & $112.3(106.8-117.8)^{\mathrm{e}}$ & $105.2(101.0-109.4)$ & $<.0001$ \\
& Girls & $111.6(108.5-114.8)^{\mathrm{bd}}$ & $109.8(105.0-114.6)$ & $107.0(102.5-111.5)$ & .1075 \\
Peak 30-minute & Both & $80.4(76.8-84.1)^{\mathrm{d}}$ & $77.5(72.9-82.2)$ & $73.1(68.9-77.3)$ & $<.0001$ \\
& Boys & $84.8(81.0-88.7)^{\mathrm{d}}$ & $80.3(74.2-86.4)^{\mathrm{e}}$ & $73.1(68.3-77.9)$ & $<.0001$ \\
& Girls & $76.0(72.2-79.9)^{\mathrm{b}}$ & $74.7(69.3-80.1)$ & $73.2(68.0-78.4)$ & .4642 \\
Peak 60-minute & Both & $66.5(63.3-69.7)^{\mathrm{d}}$ & $63.3(59.0-67.5)$ & $59.9(56.1-63.7)$ & $<.0001$ \\
& Boys & $71.3(67.8-74.8)^{\mathrm{cd}}$ & $66.0(60.4-71.6)$ & $60.4(56.0-64.8)$ & $<.0001$ \\
& Girls & $61.7(58.2-65.1)^{\mathrm{b}}$ & $60.5(55.6-65.5)$ & $59.3(54.6-64.0)$ & .5347 \\
\hline
\end{tabular}

BF\%: body fat percentage. ${ }^{\text {a }}$ Trend in least-squared means across BMI-defined weight status categories; ${ }^{\mathrm{b}}$ significant difference between boys and girls $(\mathrm{p}<.05)$; ${ }^{\mathrm{c}}$ significant difference between normal weight and overweight $(\mathrm{p}<.05)$; ${ }^{\mathrm{d}}$ significant difference between normal weight and obese $(\mathrm{p}<.05) ;{ }^{\mathrm{e}}$ significant difference between overweight and obese $(\mathrm{p}<.05)$.

Table 4. Adjusted analyses between peak cadence indicators, BMI and BF\% in Brazilian children.

\begin{tabular}{lcccccc}
\hline \multirow{2}{*}{ Peak cadence indicators } & \multicolumn{3}{c}{ BMI $\left(\mathbf{k g} / \mathbf{m}^{2}\right)$} & \multicolumn{3}{c}{ BF\% } \\
\cline { 2 - 7 } & $\boldsymbol{\beta}$ coefficient & $\mathbf{9 5 \% ~ C I}$ & p-value & $\boldsymbol{\beta}$ coefficient & $\mathbf{9 5 \% ~ C I}$ & p-value \\
\hline Peak 1-minute & -.102 & $-.129,-.074$ & $<.0001$ & -.203 & $-.259,-.146$ & $<.0001$ \\
Peak 30- minute & -.073 & $-.099,-.046$ & $<.0001$ & -.151 & $-.205,-.097$ & $<.0001$ \\
Peak 60- minute & -.078 & $-.107,-.049$ & $<.0001$ & -.166 & $-.224,-.107$ & $<.0001$ \\
\hline
\end{tabular}

Adjustment: sex and school; BMI: body mass index; BF\%: body fat percent; CI: confidence interval.

strated significant differences between each of the peak cadence indicators and BMI or BF\%-defined weight status in the total sample and in boys when analyzed separately. Only the peak 1-minute cadence differed significantly across $\mathrm{BMI}$ and $\mathrm{BF} \%$ weight status categories in girls. Boys consistently achieved significantly higher mean values for each of the peak cadence indicators compared to girls. We found significant negative associations between each of the peak cadence indicators and $\mathrm{BMI}$ or $\mathrm{BF} \%$ continuous variables when controlling for sex and school.

This study supports previous research that has shown negative relationships between peak cadence indicators and weight status ${ }^{17,36}$. For example, Jago et al. ${ }^{36}$ divided American boys aged 11-15 years into groups of normal weight (BMI $<85^{\text {th }}$ percentile) and at risk of being overweight (BMI $\geq 85^{\text {th }}$ percentile) and reported that normal weight children achieved significantly higher mean steps/min values during continuous slow walk (121.0 versus 110.1 steps/min), fast walk (129.4 versus 122.5 steps/min), and running (168.6 versus 153.2 steps/min) compared with children at risk of being overweight. Our results demonstrated that normal weight boys (defined by $\mathrm{BMI}$ as $\leq 1 \mathrm{SD}$ ) had higher peak 1-minute (118.8 versus 107.1 steps/min), 30-minute (86.0 versus 74.9 steps $/ \mathrm{min})$ and 60 -minute (72.4 versus 62.0 steps $/ \mathrm{min}$ ) free-living cadence than overweight children $(\mathrm{p}<.0001)$.

Barreira et al. ${ }^{17}$ analyzed the 2005-2006 NHANES data and showed that normal weight (defined as $<85^{\text {th }}$ percentile BMI) boys and girls (combined) had higher peak cadence (peak 1-minute, 30-minute and 60-minute) than those defined as obese $\left(\geq 95^{\text {th }}\right.$ percentile BMI). For example, for peak 60-minute cadence, children with normal weight BMI had a mean of 73 steps/ min and obese children had a mean of 67 steps/ min; however, in the peak 30-minute and peak 60-minute cadences there were no mean differences between overweight and obese. Our study reported that children classified as overweight/ obese had lower values for all peak cadence indicators than normal weight children by BMI status and we found similar differences in peak 60-minute cadence between BMI-defined nor- 
mal weight (67.1 steps/min) and obese children (60.7 steps/min).

We found significant negative associations between weight status and each of the peak cadence indicators. Our decision to link peak cadence indicators to sex-specific weight status cut points (BMI and $\mathrm{BF} \%$ ) $^{33,34}$ discriminating normal weight and overweight/obesity is justified based on the overwhelming evidence of an increasing world-wide obesity epidemic ${ }^{1}$ and further supported by the statistical differences in peak cadence indicators identified herein between sex and BMI and BF\%-defined weight status categories. There were significant differences in peak cadence indicators across weight status (BMI: normal weight versus overweight and obesity; BF\%: normal weight versus obesity) categories for boys, but in girls only the peak 1-minute cadence indicator differed between normal weight and obesity (BMI and BF\%). Girls appeared to be homogeneously lower in their "best natural effort" regardless of weight status category, especially for the peak 30-minute and 60-minute cadence indicators, which are shaped not only by intensity of effort but also by relative "persistence" of this behavior, whereas peak 1-minute is not similarly shaped by such persistence.

In the present study, boys had significantly higher mean values for each of the peak cadence indicators than girls. Our findings agree with recent studies that boys accumulate more steps/ day than girls ${ }^{17,37,38}$. Barreira et al. ${ }^{17}$ demonstrated differences between the sexes only for peak 60 -minute cadence ( 73 steps/min for boys versus 70 steps/min for girls). The authors found no significant differences in peak 1-minute or peak 30-minute cadence indicators by sex. Recently, Barreira et al. ${ }^{38}$ reported sex-and-age specific normative values of peak 60-minute for children and adolescents from United States using data from the 2005-2006 NHANES and found that boys take 74.5 steps/min and girls take 72 steps/ min. In a review article attempting to answer how many steps/day are enough for children and adolescents, Tudor-Locke et al. ${ }^{37}$ indicated that, on average, boys and girls take 12 000-16 000 and 10 000-13 000 total steps/day, respectively.

Findings presented here suggest a strong relationship between peak cadence and weight status independent of sex and school. We reported negative associations between each of the peak cadence indicators studied and both $\mathrm{BMI}$ and $\mathrm{BF} \%$. Similarly Gardner et al. ${ }^{16}$ reported sex-adjusted differences in daily average cadence related to presence or absence of metabolic syndrome (14.9 versus 13.6 steps/min) in children, adolescents, and young adults. The lower values for peak cadence indicators in obese children should also be related to lower daily energy expenditure of physical activity ${ }^{39}$, setting the stage for long-term positive energy balance and exacerbating further increases in body weight and fatness. Collectively, our results support the notion that intensity of physical activity expressed as peak cadence indicators is an important factor in distinguishing between normal weight, overweight and obese children. This is further supported by studies showing that time spent in MVPA is protective against developing weight status in children ${ }^{2,40,41}$.

Weight status is an important correlate of daily ambulation patterns in children. BMI and BF\% were both significantly and negatively associated with each peak cadence indicator. These results indicate that participants with high levels of body fat ambulate at lower peak cadences than those with less body fat ${ }^{16}$. Our findings agree with others that have reported a strong association between obesity and accelerometer-determined physical activity ${ }^{2,40}$.

The strengths of this study include the objective measurement of peak cadence indicators and the measurement of body fat using bioelectrical impedance in Brazilian children. These techniques and approaches are rare in Brazil where most previous research has relied upon indirect measures of physical activity collected by questionnaires ${ }^{42-44}$. This is the first study that has used multi-level modeling to examine the relationship between peak cadence indicators and weight status in Brazilian children; however, there are some limitations of this study that must be acknowledged. The cross-sectional nature of this study prevents determination of whether these associations are in some way causal or whether physical activity may be a marker of some other lifestyle factors (e.g., dietary factors or socioeconomic status) that may influence these weight status variables. Another limitation is that step-counting devices, including waist-worn accelerometers, do not quantify nonambulatory physical activity (e.g., resistance training, swimming) that could also be considered moderate intensity, and therefore may underestimate the total amount of daily physical activity performed to some extent. This is a descriptive study of step accumulation patterns of children from São Caetano do Sul, Brazil. Since this analysis shows a relationship between these peak cadence indicators and BMI and $\mathrm{BF} \%$, it is important now to move beyond the descriptive epidemiology to examine their 
relationship with other health parameters using cross-sectional, longitudinal, and intervention study designs.

\section{Conclusion}

This analysis of the ISCOLE accelerometry data represents the first examination of the relationship between peak cadence indicators and BMI and BF\%-defined weight status in children from São Caetano do Sul, Brazil.

The present study provided evidence of significant negative associations between BMI as well as $\mathrm{BF} \%$ and peak cadence indicators (peak 1-minute, 30-minute and 60-minute) among 10- year old Brazilian children, independent of sex and school. We reported significant differences in each of the peak cadence indicators across BMI or $\mathrm{BF} \%$-defined weight categories in the total sample and in boys. Only the peak 1-minute cadence differed significantly across BMI and BF\% weight status categories in girls. Boys had higher values for all peak cadence indicators than girls in the normal weight category.

Further research is needed to continue to develop means of gathering more comprehensive data in order to better elucidate the full nature of the correlates of obesity. These reference data are novel and important and can be used for surveillance, tracking, comparison, screening, intervention, and evaluation purposes.

\section{Collaborations}

GLM Ferrari conceived, designed, and implemented the study, collected and helped to write and revise the manuscript; T Araújo, LC Oliveira and VKR Matsudo helped to implement the study and to write the manuscript; E Mire performed statistical analyses and interpreted the data; T Barreira was responsible for the data collection, helped implement the study, and helped to write the manuscript; C Tudor-Locke interpreted the data, and helped to write and revise the manuscript; PT Katzmarzyk was responsible for coordinating the study and contributed to the intellectual content. All authors contributed to the study design, critically reviewed the manuscript and approved the final version.

\section{Acknowledgments}

The authors thank the participants, their parents and guardians, the teachers and coordinators of Municipal Secretary Education of São Caetano do Sul and the Municipal Government of São Caetano do Sul.

ISCOLE is funded by The Coca-Cola Company. The funder had no role in study design, data collection and analysis, decision to publish, or preparation of the manuscript. 


\section{References}

1. Marie Ng, Fleming T, Margaret Robinson, Thomson B, Graetz N, Margono C, Mullany EC, Biryukov S,Abbafati C, Abera SF, Abraham JP, Abu-Rmeileh NME, Achoki T, AlBuhairan FS, Alemu ZA, Alfonso R, Ali MK, Ali R, Guzman NA, Ammar W, Anwari P, Banerjee A, Barquera S, Basu S, Bennett DA, Bhutta Z, Blore J, Cabral N, Nonato IC, Chang JC, Chowdhury R, Courville KJ, Criqui MH, Cundiff DK, Dabhadkar KC, Dandona L, Davis A, Dayama A, Dharmaratne SD, Ding EL, Durrani AM, Esteghamati A, Farzadfar F, Fay DFJ, Feigin VL, A Flaxman A, Forouzanfar MH, Goto A, Green MA, Gupta R, Hafezi-Nejad N, Hankey GJ, Harewood HC, Rasmus, Hay S, Hernandez L, Husseini A, Idrisov BT, Ikeda N, Islami F, Jahangir E, Jassal SK, Jee SH, Jeffreys M, Jonas JB, Kabagambe EK, Khalifa AEAH, Kengne AP, Khader YS, Khang YH, Kim D, Kimokoti RW, Kinge JM, Kokubo Y, Kosen S, Kwan G, Lai T, Leinsalu M, Li Y, Liang X,Liu S, Logroscino G, Lotufo PA, Lu Y, Ma J, Mainoo NK, Mensah GA, Merriman TR, Mokdad AH, Moschandreas J, Naghavi M, Naheed A, Nand D, Narayan V, Nelson EL, Neuhouser ML, Nisar MI, Ohkubo T, Oti SO, Pedroza A, Prabhakaran D, Roy N, Sampson U, SeoH, Sepanlou SG, Shibuya K, Shiri R, Shiue I, Singh GM, Singh JA, Skirbekk V, Stapelberg NJC, Sturua L, Sykes BL, Tobias M, Tran BX, Trasande L, Toyoshima H, van de Vijver S, Vasankari TJ, Veerman JL, Velasquez-Melendez G, Prof Vasiliy VV, Vollset SE, Vos T, Wang C, Wang $\mathrm{X}$, Weiderpass E, Werdecker A, Wright JL, Yang YC, Yatsuya H, Yoon J, Yoon SJ, Zhao Y, Zhoun M, Zhurof S, Lopez AD, Murray CJL, Gakidou E. Global, region$\mathrm{al}$, and national prevalence of overweight and obesity in children and adults during 1980-2013: a systematic analysis for the Global Burden of Disease Study 2013 Lancet 2014; 384(9945):766-781.

2. Jimenez-Pavon D, Kelly J, Reilly JJ. Associations between objectively measured habitual physical activity and adiposity in children and adolescents: Systematic review. Int J Pediatr Obes 2010; 5(1):3-18.

3. Colley RC, Wong SL, Garriguet D, Janssen I, Connor Gorber S, Tremblay MS. Physical activity, sedentary behaviour and sleep in Canadian children: parent-report versus direct measures and relative associations with health risk. Health Rep 2012; 23(2):45-52.

4. Ferrari GL, Oliveira LC, Araujo TL, Matsudo V, Barreira TV, Tudor-Locke C, Katzmarzyk P. Moderate-to-vigorous physical activity and sedentary behavior: independent associations with body composition variables in Brazilian children. Pediatr Exerc Sci 2015; 27(3):380389.

5. Craig CL, Cameron C, Tudor-Locke C. CANPLAY pedometer normative reference data for 21,271 children and 12,956 adolescents. Med Sci Sports Exerc 2013; 45(1):123-129.

6. Tudor-Locke C, Johnson WD, Katzmarzyk PT. Accelerometer-determined steps per day in US children and youth. Med Sci Sports Exerc 2010; 42(12):2244-2250.

7. Schuna Junior JM, Brouillette RM, Foil HC, Fontenot SL, Keller JN, Tudor-Locke C. Steps per day, peak cadence, body mass index, and age in community-dwelling older adults. Med Sci Sports Exerc 2013; 45(5):914919.
8. Tudor-Locke C, Camhi SM, Leonardi C, Johnson WD, Katzmarzyk PT, Earnest CP, Church TS. Patterns of adult stepping cadence in the 2005-2006 NHANES. Prev Med 2011; 53(3):178-181.

9. Hoshikawa T, Toyoshima S, Ikegami Y, Mori SYS. Practical application of an actogram to physical fitness research: recording of physical activity pattern during daily life. Jpn J Phys Fit Sport 1992; 41(2):174-182.

10. Rowlands AV, Stone MR, Eston RG. Influence of speed and step frequency during walking and running on motion sensor output. Med Sci Sports Exerc 2007; 39(4):716-727.

11. Abel M, Hannon J, Mullineaux D, Beighle A. Determination of step rate thresholds corresponding to physical activity intensity classifications in adults. J Phys Act Health 2011; 8(1):45-51.

12. Rowe DA, Welk GJ, Heil DP, Mahar MT, Kemble CD, Calabro MA, Camenisch K. Stride rate recommendations for moderate-intensity walking. Med Sci Sports Exerc 2011; 43(2):312-318.

13. Harrington DM, Dowd KP, Tudor-Locke C, Donnelly AE. A steps/minute value for moderate intensity physical activity in adolescent females. Med Sci Sports Exerc 2012; 24(3):399-408.

14. Tudor-Locke C, Bassett Junior DR. How many steps/ day are enough? Preliminary pedometer indices for public health. Sports Med 2004; 34(1):1-8.

15. Bjornson KF, Song K, Zhou C, Coleman K, Myaing M, Robinson SL. Walking stride rate patterns in children and youth. Pediatr Phys Ther 2011; 23(4):354-363.

16. Gardner AW, Parker DE, Krishnan S, Chalmers LJ. Metabolic syndrome and daily ambulation in children, adolescents, and young adults. Med Sci Sports Exerc 2013; 45(1):163-169.

17. Barreira TV, Katzmarzyk PT, Johnson WD, Tudor-Locke C. Cadence patterns and peak cadence in US children and adolescents: NHANES, 2005-2006. Med Sci Sports Exerc 2012; 44(9):1721-1727.

18. Barreira TV, Katzmarzyk PT, Johnson WD, Tudor-Locke C. Walking cadence and cardiovascular risk in children and adolescents: NHANES, 2005-2006. Am J Prev Med 2013; 45(6):e27-e34.

19. Tudor-Locke C, Rowe DA. Using cadence to study free-living ambulatory behaviour. Sports Med 2012; 42(5):381-398.

20. Ferrari GLM, Araújo TL, Oliveira LC, Matsudo V. Fisberg M. Association between electronic equipment in the bedroom and sedentary lifestyle, physical activity, and body mass index of children. J Pediatr (Rio J) 2015; 91(6):574-582.

21. Ferrari GLM, Araújo TL, Oliveira LC, Matsudo VKR, Mire E, Barreira TV, Tudor-Locke C, Katzmarzyk PT. Association between television viewing and physical activity in 10-year old brazilian children. $J$ Phys Act Health 2015; 12(10):1401-1408.

22. Katzmarzyk PT, Barreira TV, Broyles ST, Champagne CM, Chaput JP, Fogelholm M, Hu G, Johnson WD, Kuriyan R, Kurpad A, Lambert EV, Maher C, Maia J, Matsudo V, Olds T, Onywera V, Sarmiento OL, Standage M, Tremblay MS, Tudor-Locke C, Zhao P, Church TS.The International Study of Childhood Obesity, Lifestyle and the Environment (ISCOLE): design and methods. BMC Public Health 2013; 13:900. 
23. Instituto Brasileiro de Geografia e Estatística (IBGE). Indicadores sociais municipais: uma análise dos resultados do universe do censo demográfico.[internet]. 2010 [acessado 2012 Jun 05]. Disponível em: http://www. ibge.gov.br/home/estatistica/populacao/censo2010/ indicadores_sociais_municipais/default_indicadores_ sociais_municipais.shtm

24. Programa das Nacoes Unidas para o Desenvolvimento (PNUD), Fundacao Joao Pinheiro (FJP). O Índice de desenvolvimento humano municipal brasileiro. Série Atlas do Desenvolvimento Humano no Brasil. Rio de Janeiro: PNUD, FJP, IPEA; 2013.

25. Trost SG, Loprinzi PD, Moore R, Pfeiffer KA. Comparison of accelerometer cut points for predicting activity intensity in youth. Med Sci Sports Exerc 2011; 43(7):1360-1368.

26. Colley R, Connor Gorber S, Tremblay MS. Quality control and data reduction procedures for accelerometry-derived measures of physical activity. Health Rep 2010; 21(1):63-69.

27. Masse LC, Fuemmeler BF, Anderson CB, Matthews CE, Trost SG, Catellier DJ, Treuth M. Accelerometer data reduction: a comparison of four reduction algorithms on select outcome variables. Med Sci Sports Exerc 2005; 37(11 Supl.):S544-554.

28. Choi L, Liu Z, Matthews CE, Buchowski MS. Validation of accelerometer wear and nonwear time classification algorithm. Med Sci Sports Exerc 2011; 43(2):357-364.

29. Barreira TV, Schuna JM, Jr., Mire EF, Katzmarzyk PT, Chaput JP, Leduc G, Tudor-Locke C. Identifying children's nocturnal sleep using 24-h waist accelerometry. Med Sci Sports Exerc 2015; 47(5):937-943.

30. Le Masurier GC, Tudor-Locke C. Comparison of pedometer and accelerometer accuracy under controlled conditions. Med Sci Sports Exerc 2003; 35(5):867-871.

31. Lohman T, Roche AF, Martorell RE. Anthropometric Standardization Reference Manual. Champaign: Human Kinetics; 1988.

32. Barreira TV, Staiano AE, Katzmarzyk PT. Validity assessment of a portable bioimpedance scale to estimate body fat percentage in white and African-American children and adolescents. Pediatric Obes 2013; 8(2):e29-32.

33. de Onis M, Onyango AW, Borghi E, Siyam A, Nishida C, Siekmann J. Development of a WHO growth reference for school-aged children and adolescents. Bull World Health Organ 2007; 85(9):660-667.

34. McCarthy HD, Cole TJ, Fry T, Jebb SA, Prentice AM. Body fat reference curves for children. Int J Obesity 2006; 30(4):598-602.

35. Statistical. Statistical Analysis System (SAS) for Windows. Release 6.12. Cary: SAS Institute Inc;1996.
36. Jago R, Watson K, Baranowski T, Zakeri I, Yoo S, Baranowski J, Conry K. Pedometer reliability, validity and daily activity targets among 10 - to 15 -year-old boys. $J$ Sports Sci 2006; 24(3):241-251.

37. Tudor-Locke C, Craig CL, Beets MW, Belton S, Cardon GM, Duncan S, Hatano Y, Lubans DR, Olds TS, Raustorp A, Rowe DA, Spence JC, Tanaka S, Blair SN. How many steps/day are enough? for children and adolescents. Int J Behav Nutr Phys Act 2011; 28(8):78.

38. Barreira TV, Schuna Junior JM, Mire EF, Broyles ST, Katzmarzyk PT, Johnson WD, Tudor-Locke C. Normative steps/day and peak cadence values for united states children and adolescents: National Health and Nutrition Examination Survey 2005-2006. J Pediatr 2015; 166(1):139-143.

39. Jago R, Ness AR, Emmett P, Mattocks C, Jones L, Riddoch CJ. Obesogenic diet and physical activity: independent or associated behaviours in adolescents? Public Health Nutr 2010; 13(5):673-681.

40. Lee S, Kuk JL, Hannon TS, Arslanian SA. Race and gender differences in the relationships between anthropometrics and abdominal fat in youth. Obesity 2008; 16(5):1066-1071.

41. Basterfield L, Pearce MS, Adamson AJ, Frary JK, Parkinson KN, Wright CM, Reilly JJ; Gateshead Millennium Study Core Team. Physical activity, sedentary behavior, and adiposity in English children. Am J Prev Med 2012; 42(5):445-451.

42. Rezende LF, Azeredo CM, Canella DS, Claro RM, de Castro IR, Levy RB, Luiz Odo C. Sociodemographic and behavioral factors associated with physical activity in Brazilian adolescents. BMC Public Health 2014; 14:485.

43. Bracco MM, Colugnati FA, Pratt M, Taddei JA. Multivariate hierarchical model for physical inactivity among public school children. J Pediatr (Rio J) 2006; 82(4):302-307.

44. Ceschini FL, Andrade DR, Oliveira LC, Araujo Junior JF, Matsudo VK. Prevalence of physical inactivity and associated factors among high school students from state's public schools. J Pediatr (Rio J) 2009; 85(4):301306.

Artigo apresentado em 04/11/2015

Aprovado em 29/03/2016

Versão final apresentada em 31/03/2016 